Article

\title{
Networked Co-Curation: An Exploration of the Socio-Technical Specificities of Online Curation
}

\author{
Annet Dekker ${ }^{1,2, *}$ and Gaia Tedone ${ }^{2}$ \\ 1 Faculty of Humanities, Archival and Information Studies, University of Amsterdam, 1012 XT Amsterdam, \\ The Netherlands \\ 2 Centre for the Study of the Networked Image, London South Bank University, London SE1 0AA, UK \\ * Correspondence: adekker@uva.nl
}

Received: 10 May 2019; Accepted: 5 July 2019; Published: 8 July 2019

check for updates

\begin{abstract}
Online curation is shaped and defined not merely by its content, but just as much by the nature of the structure and the systems that are used by curators and artists. It could be argued that this applies to any medium, but as this essay will show, the Web profoundly influences the role of the curator in new ways. In this paper we show how curation on the Web is not merely concerned with presenting art, but that curation functions within a wider ecology of social and technical power relations. This shift is characterized by a collision of different interests driven by economic, cultural, and socio-political agendas, and can be framed as a new space of performativity: signaling a move from curating a set of objects to a conceptual and operational process that puts different constellations of human and machinic agents, objects and practices into relation with one another. This means that a curator needs to take into account a complex interrelated network of dependencies and contexts that are often invisible or incomprehensible to most people. In such a scenario online curation becomes 'networked co-curation' and shifts the attention from what is produced to how it is performed under the socio-technical conditions and relations that characterize the current state of the Web.
\end{abstract}

Keywords: online curation; curating; aesthetics; processes; network; art; exhibition

\section{Introduction}

Curators have experimented with online exhibitions since the earliest days of the Web, sometimes to support or contextualize artistic practices, at others to encourage artistic experimentation, either by exhibiting existing or commissioning new work, for instance, äda'web (1994-1998), gallery 9 (1997-2003), Whitney Artport (2002-ongoing), and Tate's Intermedia Art (2000-2011). At the same time, artists organized their own online exhibition spaces out of a curiosity to explore the possibilities of the Web, for example C@C by Eva Grubinger and Thomax Kaulmann (1993-1995), or as a provocation to counter the conventional ways museum curators were making online net art exhibitions. Net artist Olia Lialina highlights one of the main differences of most museums' attempts to create online exhibitions and those of artists. According to Lialina the artists' online exhibitions emphasized the Web environment in their curatorial efforts, while museums would merely show works from their server rather than linking to the artist's server. As she mentions in relation to her project The Last Real Net Art Museum (2000), which was "a provocation to museums who in the late 1990s and early 2000s started making their own online net art exhibitions and collections-and at first they seemed to succeed, but it turned out they didn't" (Dekker 2016). ${ }^{1}$ When addressing specifics of the Web, for instance hyperlinking or circulation,

1 The Last Real Net Art Museum was a self-reference to Lialina's project First Real Net Art Gallery (1999) where she tried to sell net art. 
an online exhibition would be the result of complex interactions between various differentiated systems of creation and presentation that provide meaning through often invisible, or implicit and interrelated processes. Similarly, Lialina talks about the early days of the Web in the 1990s as

a very special moment in history when to be an artist was to be a curator, a system administrator, an art critic, an archivist or a vandal of your own work. But net artists were not the only ones to experience it. Actually everyone who was making their first web pages at the time was diving into an ocean of unknown, unexpected occupations. (Quaranta 2016)

In this sense it is perhaps not surprising that the slogan 'everyone's a curator' gained prominence only ten years after the Web started. ${ }^{2}$ Yet, as described by curator and researcher Michelle Kasprzak, here "'Curating' is increasingly being used to describe an expanding body of activity in terms of new platforms and materials, but remains focused on the act of the curator as editor or selector" (Kasprzak 2008). Kasprzak's description resembles that of the curator as "future filter feeder" — a term coined by Anne-Marie Schleiner to label the new role of the online curator (Schleiner 2003). What these descriptions fail to highlight, not unlike the online exhibitions curated by contemporary art museums, is the extensive work and the socio-technical relations that are involved in exhibiting art on the Web. ${ }^{3}$

While we acknowledge these historical lineages and value the inputs of the resulting theoretical discourses, ${ }^{4}$ in this essay we focus on the computational intricacies of the Web and how the 'lightness' of applications and interfaces and their aesthetic values, together with the 'heavy' precision of human-technical creation and systems involved in the production of cultural works, relate to the reframing of the role of the curator. ${ }^{5}$ In an attempt to emphasize the variety of functions and alliances involved in online curation, this essay pays attention to the ways in which online curation is shaped and defined not merely by its content, but just as much by the nature of the structure and the systems - computational platforms, databases, algorithms, software-that are used by curators, whoever, or whatever, they may be. ${ }^{6}$ Analyzing two examples, the curated project \#exstrange (2017) on the commercial platform eBay and DeliNear.Info (2014-ongoing) a custom-build social media site, we argue that curation on the Web functions within a wider ecology of social and technical relations. Based on an analysis of these examples we argue that online curation is more than anything 'networked co-curation', which as we will emphasize is formed by an alliance between a curator, objects, users, and machine. ${ }^{7}$ With this term we extend the proposition of the curator operating as a 'node' (Graham and Cook 2010, p. 158) within a wider media ecology and stress the importance of rethinking the curatorial, not merely as a counter-strategy to models of conventional curation, but as a concept to reconsider the influence different systems (human and machinic) exert on curatorial practices. This means that a curator needs to take into account a complex interrelated network of dependencies and contexts that are often invisible or incomprehensible to most people, but which are of crucial

2 This slogan was the title of the panel 'Everyone's a Curator: Do Museums Still Matter?' at SXSW Interactive Conference in 2014.

3 Nor does it credit the developments that happened in the discourse around curatorship more generally, for more information, see, for instance, O’Neill (2007).

4 Most discussions of exhibitions of online art or net art are about the presentation of these artworks either in relation to physical spaces, see for instance Paul (2008); Graham and Cook (2010); and Graham (2014), about repositioning the problem of curatorial agency within the digital realm, see among others, Krysa (2006), or address the art historical problem of Internet art, see among others, Stallabrass (2003).

5 Here we refer to Goriunova's notion of 'light heavy weight curating' (Goriunova 2013), which we will unpack more in the following sections.

6 It could be argued that this applies to any medium, but as this essay will show, this influence is most clearly manifest in the ever-evolving online environment of the Web.

7 Drawing upon her analysis of the project \#exstrange, Tedone $(2017,2019)$ employs the term 'network co-curation' to refer to a collaborative mode of online curation which operates through the formation of strategic alliances between human and machinic agents. She adopted (and adapted) the term from digital scholar Sabharwal (2012) who uses it to refer to innovative outreach practices in archives and museums that use social media and other Web 2.0 technologies to curate online collections. Dekker (2017) further explores the concept by proposing the term 'networked co-archiving' in her earlier discussion of the project DeliNear.Info. In this essay Tedone and Dekker's parallel explorations of the concept are integrated via a discussion of both projects. 
importance to the making and presenting of art and exhibitions. This introduces alternative ways of thinking about what an online exhibition could mean, while simultaneously showing the creative usage of online platforms. The shift from online curation to 'networked co-curation', we argue, is characterized by a collision of different interests driven by economic, cultural, and socio-political agendas, and can be framed as a new space of performativity: signaling a move from art objects to art processes. In other words, 'networked co-curation' shifts the attention from what is produced to how it is performed under the socio-technical conditions and relations that characterize the current state of the Web.

In what follows, we will provide a brief genealogy of the concept of online curation, setting the framework for the analysis of the project \#exstrange as an example of curatorial intervention dealing with the infrastructures and operative protocols of the commercial platform eBay. This will be interweaved with a theoretical exploration of the concept of 'platform' to highlight how the latter functions as a technical and economic model that engenders a specific kind of creative and aesthetic production. By examining Tedone's proposition to co-curate in partnership with the eBay algorithm, the notion of network co-curation will be put forward and further explored through an analysis of Harm van den Dorpel's project DeliNear.Info (2014), which provides an exemplary case of how the human and machinic relation is embedded within the technical layers of online databases.

\section{Online Curation}

In the last two decades the understanding of the curatorial function has been applied far beyond the conventional art worlds. While the literature from the field of curatorial studies (Levi Strauss 2006; O'Neill 2007; Smith 2015) continues to validate the role of the curator as a cultural operator and as a "free agent, capable of almost anything" (Levi Strauss 2006), within the work of creative entrepreneurs and business scholars the term is used to signify the savvy use of data aggregation tools and real-time technology to accrue competitive advantage within the online marketplace (Rosenbaum 2011; Dale 2014; Balzer 2015). Rather than dismissing such hybridization, this essay considers it the foundation of online curation.

In 2007, curator and art historian Paul O'Neill described how the role and function of a curator has changed throughout history, more recently from the "carer [of artworks] to a curator who has a more creative and active part to play within the production of art itself" (O'Neill 2007, p. 15). The rise and increasing popularity of the verb 'to curate' marked this "curatorial turn" (Farquharson 2003 , p. 8). The conventional model of curating and exhibition making more and more embraced "dialogical practices in which the processual and serendipitous overlap with speculative actions and open-ended forms of production" (O’Neill and Wilson 2015, p. 12). Stretching the boundary of curating beyond exhibition making, curation developed into a performative method and opened up new opportunities to rethink the dynamic of knowledge formation within the scope of both independent curatorial projects (Sheikh 2015), as well as museological practices within networked culture (Walsh 2016). The curatorial turn contributed to establishing the curator as a figure of authority within contemporary art worlds and created specialized fields of knowledge in which different curatorial practices developed. ${ }^{8}$ The rise of critical reflection and the historization of the curator coincided with the interest in educational programs and courses in curation. While still in development and

8 See, for instance, the curator as 'creator' (Altshuler 1994, p. 236). Building on critical historical debates, O'Neill makes a further distinction between: 1 . The Biennial, or nomadic, curator who operates between the 'local' and the 'global' and produces event-exhibitions that shape new social, cultural, and political relations in a globalized world $\left(\mathrm{O}^{\prime} \mathrm{Neill} 2007\right.$, pp. 16-17); 2. The curator as a 'meta/artist' and the artist as 'meta/curator'; the former regards the exhibition or event as an artistic product and the latter represents and self-exhibits his/her own work (ibid., pp. 22-24); 3. 'The Curatorial', understood as a research-based dialogical practice in which the focus is on open-ended forms of production $\left(\mathrm{O}^{\prime} \mathrm{Neill}\right.$ and Wilson 2015, p. 12). With regard to the latter concept, Von Bismarck et al. (2012) also reflect extensively on the emergent discussion of the curatorial with a particular focus on the dynamic reconceptualization of the roles and relations between the multiple actors taking part in curation. 
slowly building on shaky historical grounds, this discourse became specific to the curatorial field, and particularly focused on contemporary art curation. As $\mathrm{O}^{\prime} \mathrm{Neill}$ stressed, the curatorial discourse became self-referential and hermetic at times (O'Neill 2007, p. 26). Interestingly, around the time that the figure of the curator gained attention, the World Wide Web developed and with it an increased visibility of media arts practices and exhibitions. ${ }^{9}$ Surprisingly, these two developments remained separate discourses: a separation that has been referred to as a "digital divide" by art critic Claire Bishop (Bishop 2012). ${ }^{10}$

Yet despite the lack of crossover, it is generally agreed that the conventional role and status of the curator is hard to maintain on the Web (Stallabrass 2003) and that curatorship as a practice is trying to catch up with technical phenomena unfolding on the Web at full speed (Goriunova 2012). To come to terms with the new role of the curator, and perhaps to distinguish it from the contemporary art curators, new concepts emerged such as "immaterial curating" (Krysa 2006), “distributed curating" (Krysa 2008, 2013), "computer-aided curating" (Grubinger 2006), and "post-human curating" (Tyzlik-Carver 2016, 2017). In particular, Tyżlik-Carver makes a convincing case for an expansive approach to curating that weaves together references from different disciplinary fields. In her genealogy of curating, she takes into account the lineage of 1960's conceptual art and curatorial experiments, traces its evolution through the concept of 'the curatorial' and couples it with more recent insights coming from the perspectives of cybernetics and system theory through the work of the earlier-mentioned curators and media scholars such as Krysa and Goriunova. Yet, as Goriunova also highlighted, adding new terms to the genealogy of curating does not necessarily constitute a productive move. As she provokingly observes:

To my mind, the problems of such terms and the theories they put forward originate from a move to account for the previously rather disregarded part that the technical plays in the subjectification of art, while at the same time finding themselves locked in the narrow confines of a particular historically defined area of practice. With the development of digital media, the grammar of the reciprocal genesis of the technical and the cultural changes, and such change spreads in domains and dimensions beyond the field of art. (Goriunova 2012, p. 69)

Goriunova's argument calls for a shift in curatorial discourse from the field of art to networked cultures, which entails a radical rethinking of the notion of aesthetics as simultaneously a "major mode of operation for contemporary society" and a practice in a constant process of becoming whose very constitution is being changed by networked technologies (Goriunova 2012, p. 94). Rather than focusing on the aesthetic and its implications, we want to address the changes to the curatorial practice that are caused by technical influences and systems (Terranova 2004; Fuller 2005), in particular online commercial and custom-build platforms. As such, we are seeing the role of the curator shifting between the curator as an exhibition maker and a 'meta curator', 11 in which curating becomes 'networked-co-curation' and is heavily influenced by technological developments.

\section{Implications of the Web, or What It Means to Curate in a Commercial Platform}

In 2016, curators Marialaura Ghidini and Rebekah Modrak organized the curatorial project \#exstrange: a curatorial intervention on eBay. Reflecting on the auction-based platform eBay, Ghidini

9 We use the term 'media arts' here, but other similar terms have been used throughout the last decades such as 'computer arts', 'virtual art', 'digital art', to name a few. However, 'media', or 'new media art', were the most widely used.

10 Bishop's description of the digital divide has not been uncontested; especially 'new media art' curators and scholars refuted the subordinate distinction between new media art and mainstream contemporary art. Yet the discussion mostly reinforced the polemics of the 'digital divide', rather than considering the actual meaning of the term 'digital divide' (Castells 2001; Ragnedda and Muschert 2017) to rethink the relationship between aesthetics and politics within networked culture. For more information, see Tedone (2019).

11 Our use of the term 'meta-curator' diverges from $\mathrm{O}^{\prime} \mathrm{Neill}$ (2007) description in so far as it does not refer to the position of the curator in regard to artists, but rather to the curator's critical awareness of her/his imbrication within a complex network of power relationships, including technical systems. 
and Modrak orchestrated an artistic and curatorial takeover of the commercial platform. The project's curatorial structure was inspired by the Number Shows (1969-1974), a series of four international exhibitions based upon the principle of 'instructions' that were given by artist/curator Lucy Lippard. In response to Lippard's invitation, the participating artists sent her guidelines on how to assemble and install the exhibiting works on index cards. Lippard turned an economic limitation-the inability of paying for plane fares for the participating artists-into a conceptual device that challenged traditional models of display and presentation of a work of art. ${ }^{12}$ Moving beyond the physical boundaries of the white cube, Ghidini and Modrak used the model of the instructions-based exhibition in the online context, asking artists to insert their works within the categories of the e-commerce platform and to follow its preformatted templates and operating protocols. In this way, they opened up the possibility of exploring how eBay could function as a site for curatorial experimentation. Ghidini and Modrak attentively curated the project's conceptual framework, timing and documentation and adopted a decentralized curatorial model whereby several guest curators were also invited to intervene in the process. As a result, they gave away some degree of curatorial control. Following the project's inaugural slot in January 2017, they slowly faded into the background, acting as efficient 'platform builders and organizers' (Ghidini and Modrak 2017, p. 9), allowing the project to unfold by itself and for its shape to be defined over time by the interactions between the platform, its audiences and users, and the growing number of participating artists and guest curators. In this sense, they allowed the project's aesthetic force to amplify and for it to operate as an 'art platform' (Goriunova 2012). Goriunova describes an art platform as

a stand-alone website that, together with other actors, forms an ecology of aesthetic production, but it might also take place as a subsection of a large platform, or even as a space between a corporate service, artists' work, hacking, collaborative engagement, and a moment of aesthetic fecundity. An art platform engages with a specific current of techno-social creative practices and aims at the amplification of its aesthetic force. (Goriunova 2012, p. 2)

Goriunova's definition of the art platform is particularly useful in framing the role of the project within the larger media ecology of eBay. But first, what is an online platform, and secondly, in what way can a commercial platform function as an art platform?

The term 'platform' originally referred to a neutral, passive and non-political material structure, but its present meaning has become more figurative and complex (Leorke 2012). Sociologist Alberto Cambrosio and historian Peter Keating trace the historical notion of platform by showing how a platform came to be seen as "a set of ideas, objectives, and principles supporting a common course of action and upheld by a political party, a union, or any other organized group" (Cambrosio and Keating 2003, p. 27). With this shift, they argue, the term has become entangled in political and technical concepts while simultaneously pivoting progress and future orientation; not surprisingly, in the mid-noughties this rhetoric permeated the marketing campaigns of technology giants (Gillespie 2010, p. 350). Indeed, in 2005, Tim O'Reilly and John Battelle coined the phrase 'the web as platform' as the core principle of Web 2.0, thereby giving the notion of 'platform' a renewed, albeit flattened, meaning which foremost describes it as a conglomerate of technical development. A few years later in 2009, Ian Bogost and Nick Montfort laid the foundations for a theoretical framework that became known as 'platform studies'. Extending the concept of platform into game design, they argue for the "most neglected" level in analyses of digital media: the platform, or the underlying "computing systems and computer architecture" of digital technologies (Bogost and Montfort 2009, p. 147). ${ }^{13}$

12 Lippard never saw herself as a curator, but her exhibition model broke new ground and has since then been assimilated into the genealogy of curating, shaping both its historical (Obrist 2008; O'Neill 2012) and more recent discourse and practice (Tyzlik-Carver 2016, 2017).

13 Interface Studies also developed around the same time; while both give accounts of online platforms their theoretical and conceptual framework are slightly different, yet there are also many similarities in the analysis of cases. For more information see, among others, Plantin et al. (2016). 
In general, platform studies analyze the ways in which platforms are created, in a material sense, while also taking into account the (implications for) cultural and social concerns. As described by Bogost and Montfort:

Platform is the abstraction level beneath code, a level that has unfortunately received some attention and acknowledgement, but which has not yet been systematically studied. If code studies are new media's analogue to software engineering and computer programming, platform studies are more similar to computing systems and computer architecture, connecting the fundamentals of digital media work to the cultures in which that work was done and in which coding, forms, interfaces, and eventual use are layered upon them. (Bogost and Montfort 2009, p. 147, original emphasis)

In her thesis 'The Web as Platform. Data Flows in Social Media' (2015), media studies scholar Anne Helmond makes a further distinction in which she sees platforms operating within a 'double logic'. She explains how, on the one hand, platforms are based on an infrastructural model that stresses their technical construction, which is "geared towards their expansion into the rest of the web" (Helmond 2015 , p. 3). Furthermore, she explains how at the same time they function as economical models by employing and reformatting data for the platforms themselves (Helmond 2015, p. 44), preferably capitalizing on the process. While recognizing this 'double logic', Goriunova focuses particularly on the creative production in online platforms. Rather than looking for art online, she investigates practices that do not necessarily see themselves as art, yet their modes of production and the processes through which these practices can make them into art, thus stressing the importance of art platforms as experiments in the aesthetics of organization. Rather than a set of objects, such an experiment shows a specific kind of cultural practice that is open-ended and emerges from grassroots processes. More importantly, she describes an art platform as an entity, an activity and a process of development that reflects on its own media ecology: "Art platforms engage with living practices in their blurred and 'dirty' forms between a more broadly defined swathe of culture and art" (Goriunova 2012, p. 13), and they are to be found in the 'grey' zones of cultural production. Furthermore, she argues, art platforms make you think about the organizational forms of culture, thus it is organizational aesthetics. Organizational aesthetics is grounded in a digital environment and, while structuring and organizing creativity that traverses art platforms, it highlights the development of new forces to overcome repetition and strive for vitality. Moreover, it pays attention to the interplays of power and the kinds of structures and conduct these imply (Goriunova 2012). By acknowledging that the brilliant can be found in the grey and banal corners of the Web, \#exstrange provided an interesting opportunity to see what online curation could mean within the commercial platform eBay.

Pre-Facebook and pre-Tinder, eBay is one of the first online platforms that allowed users to interact with strangers on the Web. The platform was officially launched in 1997, two years after its founder Pierre Omidyar wrote the code for AuctionWeb (its first iteration). Soon it established itself as an open marketplace dedicated to bringing together buyers and sellers and producing "an army of bubble wrap entrepreneurs" (Lewis 2008, p. 7). In June 2000, eBay also started its 'University Learning Center' (ULC) to teach users how to become master sellers. ULC lasted until 2006, and introduced a workshop programme at eBay's headquarters in San Jose, an additional series of workshops across the US, and several online courses. Today, the company continues to engage in community building and education, through more informal programs such as 'Friends of eBay', an initiative hosted by eBay NY, which fosters entrepreneurship and networking among tech start-ups. As mentioned on the website, "\#exstrange is a curatorial project transforming eBay into a site of artistic production and cultural exchange as an artistic intervention into capitalism". ${ }^{14}$ As a response to both the conventions of the marketplace and the contemporary art system's normalization of the potential of the Web,

14 See: http://exstrange.com/. 
Ghidini and Modrak invited artists and curators to create and present artworks-as-auctions as part of \#exstrange. While they were interested in the relationships between labor, net-based media and the marketplace, one of the sub-projects curated by Tedone set out to also explore the role and function of the curator in a platform or environment that is increasingly dominated and functioning through bots and where the question 'what is a curator?' is replaced by 'who is a curator?'.

Tedone was one of the eleven curators approached by Ghidini and Modrak to be part of \#exstrange. She was to select three artists, guide them through the set of instructions provided by Ghidini and Modrak and write a curatorial statement. ${ }^{15}$ One of Tedone's main interests in the project was the role images play on eBay and how "they support the functioning of the whole marketplace, acting as interfaces among different users and enabling multiple economic and social transactions" (Tedone 2017, p. 181). ${ }^{16}$ As briefly mentioned, eBay guides potential sellers through their system by providing expert advice on profiling and creating a 'good image', meaning something that would attract the most attention from potential buyers. There was little curatorial work left to do due to the 'overtly and overly curated' project, the restrictions of the initiating curators Ghidini and Modrak, and the premise of eBay's standard operating protocols and selling categories. Yet, intrigued by the mechanisms of these systems and at the same time discovering the poor visibility of the overall project on the platform, Tedone delved into the working of eBay's analytics in an attempt to increase the audience for the auctions.

While there appeared to be no golden rule to be successful in the online marketplace, some steps could be taken to "be competitive and stay competitive" (Alexander 2013) on the platform. After examining eBay's analytics, it turned out that much of the success of the listings depended on eBay's search algorithm 'Cassini' that was introduced in 2013. ${ }^{17}$ Several YouTube tutorials can be found that show how best to use the algorithm. Essentially Cassini ranks highly listings that are honest and clear, informative, categorized correctly, and supported with excellent customer service. To foster the platform's computational culture, Cassini values engagement over everything else. The algorithm is also described as "data-driven, values-driven, shopper-oriented" (Hsiao 2017), being based upon eBay's four corporate values of 'Relevance', 'Value', 'Trust', and 'Convenience' (Hsiao 2017). If these values are observed, the visibility of a listing is optimized and long-term relationships between users are maintained. Through analyzing and understanding the effect of Cassini it became clear to Tedone that the algorithm was a crucial curatorial agent: it sorted and selected content according to criteria of relevance and managed the interactions between users (Tedone 2019). ${ }^{18}$

To find out what kind of relationship she could create, or enforce, with the algorithm and what the consequence of such a relation would be for the curator, Tedone organized another project as part of \#exstrange. This time she decided to engage in a strategic alliance with Cassini. While Cassini executes automated tasks such as searching, collating, sorting, categorizing and visualizing, the work of a human curator involves the use of specific cognitive faculties for contextualizing, interpreting, reflecting, sensing out, imagining, criticizing and inserting humor. Combining the two, Tedone set up a performance that consisted of the circulation and subsequent sale of a curatorial consultancy service

15 Tedone invited artists Niko Princen, Eva and Franco Mattes and Garrett Lynch, for a detailed description and in-depth analysis of her curatorial project, see Tedone $(2017,2019)$.

16 Unlike other 'image-based platforms' such as Pinterest, Instagram or Tumblr, eBay is not generally recognized as an 'image-based platform'. However, the functioning of its entire mechanism is precisely based upon the use of images as visual interfaces. Images are the precondition for entering the online marketplace and the discriminator for accruing competitive advantage. For more information on the intricate relationship between representation and computation of the image, see Tedone (2019).

17 Interestingly, with the implementation of the new algorithm, it became more difficult to circumvent eBay's standardized search engine as the new algorithm was targeted to follow eBay's 'best practices': how to boost customer engagement and enhance image quality. For more information, see Tedone (2019).

18 While this mimics similar algorithms used by other social platforms, such as Facebook's Edge Rank and Amazon's A9, in the case of eBay, Cassini also translates some of its findings into micro-marketing that is reflected in personalized e-mails sent by the platform to its users. For more information, see Tedone (2019). 
aimed at bridging the "gap between computation and culture" (Finn 2017a, p. 55) by addressing new forms of creativity and cooperation. ${ }^{19}$ Although the consultancy was available to all eBay users, it best fitted artists who were interested in exploring the value of their name and work on the platform. At a starting price of $\$ 15$, the service included an online report of the key findings emerging from this experimental mode of curation, the co-creation with Cassini of an eBay collection tailored to the buyer's listings and tastes, and a special mention at a public event organized at The Photographers' Gallery in London. ${ }^{20}$ As such, the service focused on two important criteria of success-visibility and criticality - which traditionally measure the relevance of an artist or an artwork. Moreover, these qualities are usually hard to quantify and control since they depend upon highly subjective and volatile criteria, such as fame, chance, taste, and market fluctuations. In this sense, Tedone also tried to engage in institutional critique of the system of art curating by addressing the role of the curator in shaping not only "public tastes but the very value system of art" (Tyzlik-Carver 2016, p. 51).

After its launch, eBay user 'Afaja', who was identified as the artist Alessandro Sambini, bought the curatorial consultancy service, as a result of which he produced and consequently sold his auction-as-artwork 'Portable Wildlife Image Instance'. The object, half a Tesco's shopping bag depicting a generic landscape, played with the tropes of contemporary landscape photography and the characteristics of a ready-made. Closely informed by the service, Sambini's auction ranked at the top of eBay search — primarily due to its original title and description and high-quality photographs-three features that had proven to be key to Cassini. After fierce competition and thirty-two different bids, user 'Temporama' bought 'Portable Wildlife Image Instance' for \$44, marking an increased market value of $40.5 \%$. The result of this auction indicated that online curation on a commercial platform does not necessarily conform to the logic of visibility, since it can easily be co-opted via the algorithm by the imperatives of profit. From here it could be concluded that at a time when, paradoxically, visibility has little to do with seeing and "can only be verified by statistical means such as polls, viewing figures and market research" (Van Winkel 2005), it is in what cannot be quantified or measured that perhaps other forms of value might be found.

The collaboration between Tedone and Cassini was both conceptual, in the sense that it worked on different levels of abstraction and imagination, and critical, since it solicited a reflection on the algorithm's 'concealed' role within the platform. At the same time, it can be characterized by a distinct material specificity since it operated as an actual service on the platform, producing economic gain for all the parties involved. However, the positive outcome of Sambini's auction may also be attributed to the convergence of two unforeseen factors which belong to an affective sphere, that of human interactions, previous knowledge and experiences, and which could not have been anticipated by the metrics of the algorithm (Tedone 2019). Moreover, the results were influenced by the previous project Tedone curated, as well as the fact that it was embedded within the \#exstrange project. As such, the project shows the impossibility of autonomous curation on the Web: either curation takes place within predefined contours that link a project back to specific systems of reference and fields, for instance, the worlds of contemporary art and new media or academia, thus perpetuating conventional institutional divides, or it risks dissolving within the plethora of online-produced content. In a sense, it could be argued that the project \#exstrange produced its own 'art filter bubble' on eBay: driven by the algorithm it became an algorithmically delineated community of artists and art professionals whose online preferences and searches qualified them as part of a particular 'group'. While this is partly true, such a statement tends

19 This way the project also engaged with recent debates in the theory and practice of human and algorithmic curation, see for instance, Krysa (2006); Paul (2006) and Tyzlik-Carver (2016, 2017).

20 It is important to note that the service Tedone used, the category 'Specialty Services $>$ eBay Auction Services $>$ Appraisal \& Authentication', is available only to customers in the US, highlighting the different national regulations that impact access and the use of the platform in different parts of the world, thus affirming the notion of 'visibility gatekeeping' (Magalhães and Yu 2017) or 'censorship' (Finn 2017a, p. 111), impacting what data-images, information and material goods-is available and to whom. Moreover, it shows how the curatorial capacity of the algorithm is inextricably linked to the wider dynamics of control over user data and the behaviours that eBay enforces. 
to ignore the multiple layers and relations that are, perhaps (un)willingly, part of online curation and which can extend and move beyond the 'group', which, as mentioned, became particularly visible as people who had more experience and earlier investments on eBay. Their previous interactions influenced the project and consequently the present actions will impact their future participation on eBay. In this sense as also argued by Goriunova:

The technical is aesthetical is political is cultural; each of these domains folds into the other and is fed back on itself. Every layer informs, embeds, and models the others, distributing their particular power patterns throughout societal systems and their blurry zones of transfer. (Goriunova 2012, p. 21)

To comprehend and navigate the complexity of today's computational culture, we argue, is necessary to step into these 'blurry zones of transfer' between the commercial and the aesthetic, between art and non-art. In this process, the role of the online curator in these examples can be compared to that of a "filter" (Paul 2006) or a "filter feeder" (Schleiner 2003), as it distils content and creates meaning by differentiating information, albeit within certain restrictions, in particular around the mechanisms of exclusion. Whether the act of filtering is engrained in the processuality of art curating and its system or in the specificity of the technology that the online curator enters into an alliance with, its effect is that of influencing the circulation of and access to cultural content among different audiences and in distinct areas of the world. At the same time, being embedded in algorithmic infrastructures, online curation comes into contact with a set of agents and power relationships that define the contexts of commercial platforms not simply as commercial spaces but also as social ones, where users interact, taste is co-produced and aesthetic germination can arise. Due to this socio-technical specificity, and shifting the focus from artists and artworks to processes and systems, online curation recasts the function of the curator; in which the curator is part of a complex network of human and technical agents, networked images, digital objects and machines.

\section{Networked Co-Curation}

Following the online aesthetic forms and the vitality of online lurking, meme creation and the popularity of vloggers, in her article 'Light Heavy Weight Curating' (2013), Goriunova further unpacks the role of the curator. She shows how curators are compelled by the production and extension of aesthetic forms, values and procedures, yet at the same time, that they are in competition, or conflict, with capitalist, deterministic and entropic forces. It is in the middle of such tensions, she argues, that shifting epicenters and boundaries can be traced and how online curation is both light and heavy weight curation.

Curators and museums working with the new computational materiality are compelled to remain lightly operational, responding to the creation of new aesthetic value, whether by artists or those beyond-artists. ( ... ) Confronted lightly and omnipresently with the new aesthetic values ceaselessly churned out by the operations of computational matter, the curator's or art institution's work is heavy. (Goriunova 2013, p. 26/28)

In other words, the 'tensions' in online curation derive from the easy to use applications, interfaces, and templates, and at the same time, the human attention that is needed to consider the implications of the cooperation with the technical systems. Rather than an automatic dismissal of algorithms to transform the practice of curation, Tedone (2019) argues in favor of the potential of human-algorithmic curation as an opportunity to explore more thoroughly algorithms' wider socio-cultural impact. This is also something media theorist Tania Bucher points out, albeit from a more negative perspective:

Algorithms matter in a variety of ways: in their capacity to govern participation on platforms, distribute information flow, embed values in design, reflect existing societal biases and help reinforce them by means of automation and feedback loops, and in their power to make people feel and act in specific ways. (Bucher 2018, p. 120) 
Consequently, she argues, "knowing algorithms might involve other kinds of registers than code" (Bucher 2018, p. 113), examples of which could be critical analysis, speculative inquiry and poetic imagination. This is something that artist Harm van den Dorpel tried to achieve in his project DeliNear.Info (2014). The project counters the scenario in which online curation would become 'darker', as less and less is known about the conditions and outcomes of algorithms and computer processes more generally. Delinear.info sits in between a sketchbook, a social platform, and an archive (Dekker 2015). The content, ranging from texts to images, audio and video, that is uploaded by each user simultaneously functions as navigation. Different users take part and while they have their own space, they can connect to each other associatively through images, sounds or texts. An intricate 'quilting' takes place in which spontaneous and associative connections can emerge between the content. Van den Dorpel developed Delinear.info because he believed that many existing social media platforms are too chronologically driven and do not enable enough freedom for expression, as the systems are too rigid and pre-set. Looking for experimentation and the unexpected, much as in the older days of the Web, Van den Dorpel sees Delinear.info as a studio, a place to try things out. As he emphasized, he is

particularly interested in how we can connect information in new, meaningful ways. In this context I mean meaningful as aesthetically surprising. I do not believe that knowledge is embedded in documents, just as that beauty is not embedded in objects. Beauty and knowledge arise through a game between the creators, viewers, contexts, historical stories, et cetera. (Dekker 2015)

Van den Dorpel approaches the Web as a recursive environment, which is all about organizational structures, conceptualization and making relationships. Emphasizing that something is never finished, that results are not fixed and that things can always change, DeliNear.Info shows how a work of art or an image does not create meaning or value by itself. It's the different relationships-joining the human/social and the technical—-that determine the value of the content. What is arguably pushing the 'boundaries' of current curatorial practices is Van den Dorpel's insistence in searching for complexity, which he finds in the layers between different systems that are connected to each other. Whereas most methods for organizing information are focused on reducing complexity, he does not try to simplify or reduce, but to encourage complexity. Most advanced search and database engines are still mainly based on text; hence there is a need to reduce complex matters to a brief summary, ideally one word. This way data can be classified and interpreted mechanically. As Van den Dorpel mentions, the interpretation from something complex to abstract qualification hinders alternative interpretations (Dekker 2015). In Delinear.info, the visual 'object' links, it stands on its own, and connections-or relations-arise from the operations that are performed on it. As a user you trace information more intuitively and aesthetically to encounter information through links, instead of following expected routings. At the same time, you can participate and upload and link the things that matter to you. Rather than a smooth fabric or relatively ordered story, images, words, sounds and sentences seem to dance around, move chaotically, form chains, and assemble into a ragged and unbounded multiple to perhaps even mutate. Perhaps over time they merge into something that starts to make new sense.

It could be argued that Delinear.info is far removed from conventional curatorial practices that are concerned with original records, objects or documents. On the one hand DeliNear.info is about uncontrolled, fragmented and patch-worked quilting. On the other hand, it attributes new values to data objects and creates new keys, enacting a specific aesthetic, human and machinic relationality. By emphasizing the performativity of a database and translating the medium-specificity into an aesthetic gesture, DeliNear.info is a curatorial performance that resembles a thickening, a saturation, of relations that are intensified, doubled, made similar, made serial, and it is from these operations that something else arises. In an environment in which data are constructed and can only be experienced in relation to other data, code, software, and hardware, which may have no obvious relation with the 'object', the platform signals the need to consider alternative ways of thinking about online curation. As emphasized by Sheikh, following Tara McDowell's 'post-occupational condition', in this space the roles, and perhaps the division of labor alongside of it, are blurred, in which "categories as artist 
and curator, thinker and programmer, director and assistant, master and student, and so on, are both willfully and intuitively obscured, if not even abandoned" (Sheikh 2017). ${ }^{21}$ To overcome, or take advantage of, this blurring and in order to survive culturally and socially, online curation should reflect on the environment in which its 'exhibitions' are created, embedded and constructed.

\section{The Powers of Online Curation}

As part of her curatorial endeavor in eBay, Tedone scrutinized and apprehended the mechanics of eBay's technical infrastructure by working simultaneously with and against the algorithm to uncover the intricate networks of production and consumption, which could potentially mobilize new forms of resistance and critique. The project also showed the role online users play in shaping the platform's culture and, finally, it involved the carving out of an autonomous space on a commercial platform where humor, poetry and play mixed together (Tedone 2017). While these aspects remained relatively subtle in Tedone's experiment with Cassini, DeliNear.Info more clearly plays with the ambiguity and ingenuity of unexpected encounters, which at times can lead to poetic or humorous associations. Both projects show how technical structures, commercial or non-commercial, to an extent predetermine the interactions between curator/artist and users. This site-specificity means that the human actors (curators, artists or users) need to reconsider the relationship between the container (the 'exhibition' space, i.e., the infrastructure), the contained (the artworks, images, or data), and the audience.

At the same time, the projects emphasize that it is important to overcome the "false dichotomy of being either for or against the algorithm" (Bucher 2018, p. 122). It is important to recognize that algorithms can be accountable for the organization and arrangement of content and, in that respect, that their actions (search, collate, group, sort, analyze, visualize) and aims (to stimulate and foster engagement on the platform) can be seen as similar to that of an online curator. Yet, the participation of the curator in this human and machinic network decentralizes dynamics of power, authority and cultural gatekeeping and allows for the development of the critical awareness and strategic operationality necessary to navigate the complex forces and entanglements that are characteristic of networked cultures (Dewdney 2019). As such, networked co-curation is a de-centralized and collaborative alternative to the dynamics of hyper-individualism and cultural gatekeeping that are often at the core of art world systems and social media platforms. Here, the curator moves from a figure of authority to being one of the nodes within a complex socio-technical assemblage of human and non-human agents. This leads to the notion of networked co-curation: an alliance between a curator, users, objects and machines.

Networked co-curation can be understood as both a theoretical concept and an operational strategy for forging a critically reflexive mode of online curation. It opens the curatorial activity to participation from human and non-human agents and largely relies on digital tools and network infrastructures. The importance of \#exstrange and DeliNear.Info is the forms of creativity that emerge as the result of unpredicted encounters on online platforms. At the same time, the projects show how online curation is performed in and through human and technical objects, relations and interactions, which are active in and simultaneously become organized through these platforms or the systems in which they operate. In this sense, they undermine what could be considered a curatorial monopoly to classify, document, display or archive artistic and aesthetic activities. In the process, they also challenge the museums' preoccupation with art objects. The notion of networked co-curation, instead, shifts

21 Since a few years the word 'post' has gained prominence, whether in post-Internet art, posthuman and posthuman curation, or simply post-curation. In most cases this is done to signal the growing abstraction and influence of geopolitics and computation. While we recognize the importance of this term, as it shows how new forms of curation emerge (particularly in relation to a redefinition of geopolitical powers and as a challenge to established or authoritative curatorial models), we also find it problematic since it postulates a temporality that tends to discard the human in favour of technology; in which the latter may be stabilized or normalized instead of critically assessed. We believe it is important to first come to an understanding of the specifics of curation, as a fusion and friction of different elements, rather than discarding the specifics of any of the elements from the beginning, particularly in environments that are continuously evolving. 
attention from what is produced and exhibited to how it is performed. In other words, it is important to rethink online curation, not merely as a counter-strategy to conventional models of curating, but as a way to reconsider the influence different systems (human and machinic) exert on curatorial practices, while introducing alternative ways of thinking about how online curation could operate under these socio-technical conditions.

As a practice in and simultaneously of the network, networked co-curation is here proposed as a space of operationality and performativity, which creates "the possibility for a complex dance of intention, anticipation, creativity and emergence based on individual people, algorithms, and the social and technical structures that bracket them all" (Finn 2017b). The role of the online curator can be found in the forging of new relationships between aesthetics and politics, one that acknowledges the increasing influence of algorithms and technology on both areas and that considers their key role as visibility gatekeepers and acknowledges the effects they produce on the structures of power and governance. This then is the space where the powers of online curation are best visible and where networked co-curation could become a method for producing cultural differentiation and valorization under the current state of privatization, corporatization and commodification of the Web.

Author Contributions: A.D., context and case study DeliNear.Info; G.T., context and case study \#exstrange.

Funding: This research received no external funding.

Conflicts of Interest: The authors declare no conflict of interest.

\section{References}

Alexander, Todd. 2013. eBay: Understanding eBay Search with Todd Alexander. Available online: https: //www.youtube.com/watch?v=I6znSUKtKH0 (accessed on 10 May 2019).

Altshuler, Bruce. 1994. The Avant-Garde in Exhibition: New Art in the 20th Century. New York: Harry N. Abrams. Balzer, David. 2015. Curationism. London: Pluto Press.

Bishop, Claire. 2012. Digital divide: Contemporary art and new media. Artforum September: 434-42.

Bogost, Ian, and Nick Montfort. 2009. Racing the Beam: The Atari Video Computer System. Platform Studies Series. Cambridge: The MIT Press.

Bucher, Taina. 2018. If... Then: Algorithmic Power and Politics. Oxford: Oxford University Press Inc.

Cambrosio, Alberto, and Peter Keating. 2003. Biomedical Platforms: Realigning the Normal and the Pathological in Late-Twentieth-Century Medicine. Cambridge: The MIT Press.

Castells, Manuel. 2001. The Internet Galaxy: Reflections on the Internet, Business, and Society. Oxford and New York: Oxford University Press.

Dale, Stephen. 2014. Content Curation: The Future of Relevance, Business Information. Business Information Review 3: 199-205. [CrossRef]

Dekker, Annet. 2015. Harm van den Dorpel: Choosing Complexity. Metropolis M. Dec/Jan 2015/2016. Available online: https://www.metropolism.com/nl/features/24054_harm_van_den_dorpel (accessed on 10 May 2019).

Dekker, Annet. 2016. A Celebration of Twenty Years on the Web: My Boyfriend Came Back from the War. Annet Dekker in Conversation with Olia Lialina. MU. February 19. Available online: http://www.mu. $\mathrm{nl} / \mathrm{en} / \mathrm{txt} / \mathrm{a}$-celebration-of-twenty-years-on-the-web-my-boyfriend-came-back-from-the-war (accessed on 10 May 2019).

Dekker, Annet. 2017. Between Light and Dark Archiving. Paper presented at RE:TRACE-7th International Conference for Histories of Media Art, Science and Technology, Krems, Vienna, Austria, November 23-25.

Dewdney, Andrew. 2019. The Networked Image: The Flight of Cultural Authority and the Multiple Times and Spaces of the Art Museum. In The Routledge International Handbook in New Digital Practices in Galleries, Libraries Archives, Museums and Heritage Sites. Edited by Hannah Lewi, Wally Smith, Steve Cooke and Dirk vom Lehn. New York: Routledge, forthcoming.

Farquharson, Alex. 2003. I Curate, You Curate, We Curate. Art Monthly September: 7-10.

Finn, Ed. 2017a. What Algorithms Want Imagination in the Age of Computing. Cambridge: The MIT Press.

Finn, Ed. 2017b. Art by Algorithm. Aeon. September 27. Available online: https://aeon.co/essays/how-algorithmsare-transforming-artistic-creativity (accessed on 10 May 2019). 
Fuller, Matthew. 2005. Media Ecologies. Materialist Energies in Art and Technoculture. Cambridge: The MIT Press.

Ghidini, Marialaura, and Rebekah Modrak, eds. 2017. \#Exstrange: A Curatorial Intervention on Ebay. Maize Books. Ann Arbor: Michigan Publishing.

Gillespie, Tarleton. 2010. The Politics of "Platforms". New Media and Society 12: 347-64. [CrossRef]

Goriunova, Olga. 2012. Art Platforms and Cultural Production on the Internet. Oxon: Routledge.

Goriunova, Olga. 2013. Light Heavy Weight Curating. In Speculative Scenarios: Or What Will Happen to Digital Art in the (near) Future? Edited by Annet Dekker. Eindhoven: Baltan Laboratories, pp. 25-32.

Graham, Bery, ed. 2014. New Collecting: Exhibiting and Audiences after New Media Art. Farnham: Ashgate Publishing Limited.

Graham, Beryl, and Sarah Cook. 2010. Rethinking Curating. Art after New Media. Cambridge: The MIT Press.

Grubinger, Eva. 2006. C@C: Computer-Aided Curating (1993-1995). In Curating Immateriality: The Work of the Curator in the Age of Network Systems. DATA Browser 3. Edited by Joasia Krysa. New York: Autonomedia, pp. 107-15.

Helmond, Anne. 2015. The Web as Platform. Data Flows in Social Media. Ph.D. dissertation, Amsterdam School for Cultural Analysis, Amsterdam, The Netherlands.

Hsiao, Aron. 2017. Make eBay's Cassini Search Work for You Understand and Manipulate eBay's Cassini Search Engine. The Balance Small Business. Available online: https://www.thebalance.com/make-ebay-s-cassinisearch-work-for-you-1140402 (accessed on 10 May 2019).

Kasprzak, Michelle. 2008. For What and for Whom? Vague Terrain, Curediting-Transrelational Online Work. Edited by CONT3XT.NET and Moderna galerija Ljubljana. October. Available online: https://web.archive.org/web/ 20141101180846/http://vagueterrain.net/journal11/michelle-kasprzak/01 (accessed on 10 May 2019).

Krysa, Joasia, ed. 2006. Curating Immateriality: The Work of the Curator in the Age of Network Systems. New York: Autonomedia Press.

Krysa, Joasia. 2008. SOFTWARE CURATING. The Politics of Curating in/as (an) Open System(s). Ph.D. dissertation, University of Plymouth, Plymouth, UK.

Krysa, Joasia. 2013. Some Questions on Curating as (Public) Interface to the Art Market. APRJA. Available online: http://www.aprja.net/some-questions-on-curating-as-public-interface-to-the-art-market (accessed on 10 May 2019).

Leorke, Dave. 2012. Rebranding the Platform: The Limitations of "Platform Studies". Digital Culture and Education 4: 257-68.

Levi Strauss, David. 2006. The Bias of the World: Curating after Szeemann \& Hopps. The Brooklyn Rail. December 8. Available online: https://brooklynrail.org/2006/12/art/the-bias-of-the-world (accessed on 10 May 2019).

Lewis, Elen. 2008. The eBay phenomenon: The Story of a Brand That Taught Millions of Strangers to Trust One Another. London: Marshall Cavendish Business.

Magalhães, João Carlos, and Jun Yu. 2017. Algorithmic Visibility: Elements for a New Media Visibility Regime. European Consortium for Political Research. Available online: https://ecpr.eu/Filestore/PaperProposal/e40a7961-0fe3-42a5-8727-f9097552f2fe.pdf (accessed on 10 May 2019).

O'Neill, Paul. 2007. The Curatorial Turn: From Practice to Discourse. In Issues in Curating Contemporary Art and Performance. Edited by Judith Rugg and Michèle Sedgwick. Bristol: Intellect.

O'Neill, Paul. 2012. The Culture of Curating and the Curating of Culture(s). Cambridge: The MIT Press.

O'Neill, Paul, and Mick Wilson, eds. 2015. Curating Research. London and Amsterdam: Open Editions/De Appel. Obrist, Hans-Ulrich, ed. 2008. A Brief History of Curating. Zurich: JRP|Ringer.

Paul, Christiane. 2006. Flexible Contexts, Democratic Filtering and Computer-Aided Curating. In Curating Immateriality: The Work of the Curator in the Age of Network Systems. DATA Browser 3. Edited by Joasia Krysa. New York: Autonomedia, pp. 85-105.

Paul, Christiane, ed. 2008. New Media in the White Cube and beyond. Curatorial Models for Digital Art. Berkeley and Los Angeles: University of California Press.

Plantin, Jean-Christophe, Carl Lagoze, Paul N. Edwards, and Christian Sandvig. 2016. Infrastructure Studies Meet Platform Studies in the Age of Google and Facebook. New Media \& Society 20: 293-10.

Quaranta, Domenico. 2016. Net.Art. The First Life of Net Art: UBERMORGEN, JODI, Vuk Ćosić, Olia Lialina. SPIKE Art Magazine. 49 (Autumn). Available online: http://www.spikeartmagazine.com/en/articles/netart (accessed on 10 May 2019).

Ragnedda, Massimo, and Glenn W. Muschert, eds. 2017. Theorizing Digital Divides. Oxon: Routledge. 
Rosenbaum, Steven. 2011. Curation Nation: How to Win in a World Where Consumers Are Creators. New York: McGraw-Hill Companies.

Sabharwal, Arjun. 2012. Networked Co-Curation in Virtual Museums: Digital Humanities, History, and Social Media in the Toledo's Attic Project. International Journal of Heritage in the Digital Era 1: 587-609. [CrossRef]

Schleiner, Anne-Marie. 2003. Fluidities and Oppositions among Curators, Filter Feeders, and Future Artists. Intelligent Agent. 3. Available online: http://www.intelligentagent.com/archive/Vol3_No1_curation_schleiner. html (accessed on 10 May 2019).

Sheikh, Simon. 2015. Towards the Exhibition as Research. In Curating Research. Edited by Paul O'Neill and Mick Wilson. London and Amsterdam: Open Editions/De Appel, pp. 32-46.

Sheikh, Simon. 2017. From Para to Post: The Rise and Fall of Curatorial Reason. Springerin, The Post-Curatorial Turn. Available online: https:/www.springerin.at/en/2017/1/von-para-zu-post/ (accessed on 10 May 2019).

Smith, Terry. 2015. Talking Contemporary Curating. New York: Independent Curators International.

Stallabrass, Julian. 2003. Internet Art: The Online Clash of Culture and Commerce. London: Tate Publishing.

Tedone, Gaia. 2017. Co-curating with Cassini: from the Abyss of Commodification to the Exploration of Space Curation. In \#exstrange: a Curatorial Intervention on eBay. Edited by Marialaura Ghidini and Rebekah Modrak. Ann Arbour: Maize Books, an imprint of Michigan Publishing, pp. 180-85.

Tedone, Gaia. 2019. Curating The Networked Image: Circulation, Commodification, Computation. Ph.D. dissertation, London South Bank University, London, UK.

Terranova, Tiziana. 2004. Network Culture. Politics for the Information Age. London: Pluto Press.

Tyzlik-Carver, Magda. 2016. Curating in/as Commons. Posthuman Curating and Computational Cultures. Ph.D. dissertation, Aarhus University, Aarhus, Denmark.

Tyzlik-Carver, Magda. 2017. | Curator | Curating | the Curatorial | Not-Just-Art Curating: A Genealogy of Posthuman Curating. Springerin, The Post-Curatorial Turn. No. 1. Available online: https://www.springerin. at/en/2017/1/kuratorin-kuratieren-das-kuratorische-nicht-nur-kunst-kuratieren/ (accessed on 10 May 2019).

Van Winkel, Camiel. 2005. The Regime of Visibility. Open! Platform for Art, Culture \& the Public Domain. April 13. Available online: https://www.onlineopen.org/the-regime-ofvisibility (accessed on 10 May 2019).

Von Bismarck, Beatrice, Joern Schafaff, and Thomas Weski, eds. 2012. Cultures of the Curatorial. Berlin: Sternberg Press.

Walsh, Victoria. 2016. Redistributing Knowledge and Practice in the Art Museum. Stedelijk Studies 4: 1-16. Available online: http://www.stedelijkstudies.com/journal/redistributing-knowledge-practice-art-museum/ (accessed on 10 May 2019). 